\title{
Pengendalian Infeksi Akar Gada pada Pembibitan Kubis dengan Pupuk Hijau Daun Paitan
}

\section{Controling Clubroot Infection on Cabbage Seedling Using Green Manure From Tithonia Leaf}

\author{
Diah Ayu Pratiwi ${ }^{1}$, Hardjono Sri Gutomo ${ }^{2}$, Hadiwiyono ${ }^{2)}$
}

\begin{abstract}
Clubroot is a major disease that often infects cabbage caused by Plasmodiophora brassicae Wor.. The leaf of T. diversifolia is an example of weeds that can be used as green leaf manure. The research aimed to study the effectiveness and dosage of green manure from Tithonia leaf to control clubroot. In planta test was conducted by using factorial completely randomized design, the first factor was dosages of Tithonia green manure and second factor was application time of fertilizing. The research showed that green manure from Tithonia leaf effectively suppressed infection of P. brassicae and was capable of increasing growth variable of cabbage seedling. Fertilizing with green leaf manure of Tithonia with dosage of 10 ton ha ${ }^{-1}$ could decreased intensity of P. brassicae infection up to $10,18 \%$. The application time of fertilizing 0 days after planting has the highest weight of cabbage seedling biomass is $14,10 \mathrm{~g}$.
\end{abstract}

Keywords : control, clubroot, cabagge, green leaf manure, Tithonia

\section{PENDAHULUAN}

Perkembangan produksi kubis di Indonesia terkendala penyakit akar gada yang disebabkan oleh cendawan Plasmodiophora brassicae Wor. Kerugian tahunan yang diakibatkan patogen penyebab akar gada di seluruh dunia mencapai $10-15 \%$ (Dixon 2009). Menurut Semangun (2007), akar gada sulit dikendalikan karena patogen dapat bertahan lama dalam tanah meskipun tanpa tanaman inang sehingga perlu adanya upaya pengembangan pengendalian yang bersifat berkelanjutan. Lungu dan Deynoodt (2008) menjelaskan bahwa penambahan bahan oganik (pupuk hijau atau sisa-sisa tanaman) menyebabkan perubahan keseimbangan mikroflora tanah yang diakui sebagai suatu pendekatan biologi yang memberikan harapan dalam perbaikan pengelolaan penyakit tular tanah.

Tithonia diversifolia atau biasa disebut daun paitan merupakan tanaman semak termasuk famili Asteraceae dapat digunakan sebagai pupuk hijau maupun kompos. Berdasarkan penelitian Jama et al. (2000), dalam $100 \mathrm{~g}$ biomassa segar tanaman paitan mempunyai kandungan unsur hara diantaranya 3,5\% $\mathrm{N}, 0,37 \% \mathrm{P}$, dan $4,1 \% \mathrm{~K}$. Daun paitan mengandung fenol, alkaloid dan tannin yang dapat dimanfaatkan sebagai antimikroba sehingga dimungkinkan mampu mengendalikan akar gada. Penelitian ini bertujuan untuk mempelajari efektifitas daun paitan sebagai pupuk hijau dan dosis pupuk hijau daun paitan yang mampu menurunkan intensitas penyakit akar gada

1) Undergraduate Student of Study Program of Agrotechnology, Faculty of Agriculture University of Sebelas Maret (UNS) in Surakarta.

${ }^{2)}$ Lecturer of Study Program of Agrotechnology, Faculty of Agriculture University of Sebelas Maret (UNS) in Surakarta.

Contact Author: ayudiaz0n3@gmail.com paling rendah serta waktu aplikasi pupuk hijau daun paitan yang tepat untuk menunjang pertumbuhan bibit kubis.

\section{METODE PENELITIAN}

Penelitian ini dilaksanakan mulai bulan Januari hingga Juni 2014 di Laboratorium Kimia dan Kesuburan Tanah, rumah kasa dan Laboratorium Hama dan Penyakit Tanaman Fakultas Pertanian Universitas Sebelas Maret Surakarta. Penelitian ini menggunakan metode eksperimental dengan rancangan penelitian yang disusun berdasarkan rancangan acak lengkap (RAL) faktorial. Faktor pertama yaitu dosis pemupukan yang terdiri dari 4 taraf yaitu: (1) kompos 6 ton ha ${ }^{-1}$ setara $2,5 \mathrm{~g}$ pupuk $\mathrm{kg}^{-1}$ tanah sebagai pembanding, (2) daun paitan 6 ton $\mathrm{ha}^{-1}$ setara 2,5 g pupuk kg $\mathrm{ganah}^{-1}$ (3) daun paitan 10 ton ha ${ }^{-1}$ setara $4,1 \mathrm{~g}$ pupuk kg-1 tanah dan (4) daun paitan 16 ton ha ${ }^{-1}$ setara $6,7 \mathrm{~g}$ pupuk $\mathrm{kg}^{-1}$ tanah. Faktor kedua yaitu waktu aplikasi pupuk terdiri dari 3 taraf yaitu: (1) 0 hari setelah tanam (HST), (2) 7 HST dan (3) 14 HST sehingga penelitian ini terdiri atas 12 kombinasi perlakuan, setiap kombinasi perlakuan diulang sebanyak 4 kali, sebagai pembanding lainnya terdapat kontrol (tanpa pemupukan).

\section{Analisis Sifat Kimia Tanah}

Analisis sifat kimia tanah dilakukan pada tanah sebelum perlakuan dan setelah bibit kubis dipanen. Analisis sifat kimia tanah yang dilakukan meliputi $\mathrm{N}$ total (metode Khjedhal), $\mathrm{P}$ tersedia (metode Bray I), $\mathrm{K}$ tersedia (metode ekstrak NH4Oac $\mathrm{pH}$ 7.0), $\mathrm{pH}$ tanah (metode Elektrometri) dan $\mathrm{C} / \mathrm{N}$ ratio.

\section{Uji In Planta Bibit Kubis \\ Persemaian dan persiapan media tanam}

Benih kubis disemaikan pada tray menggunakan media campuran cocopeat dan kompos (1:1). Benih disemaikan selama seminggu dan siap dipindah 
tanam untuk dijadikan bibit. Media tanam yang digunakan untuk pembibitan adalah campuran tanah dan kompos (1:1), kemudian media ditempatkan dalam nampan berukuran $30 \times 20 \times 10 \mathrm{~cm}$. Masingmasing nampan diisi $5 \mathrm{~kg}$ media tanam.

\section{Penyediaan inokulum $\boldsymbol{P}$. brassicae dan inokulasi patogen}

Akar kubis yang terinfeksi akar gada dicuci bersih dengan air mengalir kemudian dibilas menggunakan air steril. Akar yang telah bersih dipotong-potong dan ditambahkan aquades kemudian diblender lalu disaring menggunakan kain kasa. Suspensi yang diperoleh dihitung kerapatan sporanya hingga $10^{5}$. Volume inokulum dicampur pada media tanam adalah $10^{5}$ spora $^{-1}$ media tanam.

\section{Penyediaan pupuk hijau T. diversifolia}

Daun $T$. diversifolia yang masih segar dipotong \pm 2 $\mathrm{cm}$ bertujuan mempermudah pengaplikasian ke media pembibitan kubis dan untuk mempercepat pendekomposisian.

\section{Penanaman dan aplikasi pupuk}

Penanaman bibit dilakukan setelah kubis disemaikan 7 hari kemudian dipindahkan pada media tanam yang telah diinokulasi dengan patogen akar gada dalam bak pembibitan (nampan). Satu nampan terdapat 12 bibit kubis. Media pembibitan kubis kemudian dipupuk sesuai dengan perlakuan. Variabel yang diamati saat uji in planta antara lain tinggi dan berat segar brangkasan bibit kubis (tanpa akar). Pengamatan intensitas penyakit (IP) akar gada dilakukan dengan metode skoring sesuai dengan penelitian yang dilakukan Baharuddin et al. (2002) dengan rumus berikut:

$$
I P=\frac{\sum(n \times v)}{N \times Z} \times 100 \%
$$

$\mathrm{n}=$ jumlah tanaman yang diamati menunjukkan skor tertentu; $\mathrm{v}=$ skor untuk tanaman tertentu; $\mathrm{N}=$ skor tertinggi; $Z=$ jumlah seluruh tanaman yang diamati. Penilaian skoring $0-3 ; 0=$ tidak terdapat gejala pembengkakan; 1 = terdapat gejala pembengkakan pada akar utama; 2 = terdapat gejala pembengkakan pada akar sekunder dan; $3=$ terdapat gejala pembengkakan pada akar utama maupun sekunder

\section{Analisis Dampak Lingkungan}

Analisis dampak lingkungan dilakukan untuk mengamati populasi mikrob pada media pembibitan. Prosedur mengidentifikasi mikrob dengan menimbang contoh tanah dari masing-masing perlakuan sebanyak $1 \mathrm{~g}$ kemudian dimasukkan ke dalam tabung reaksi yang telah terisi $9 \mathrm{ml}$ air steril lalu dihomogenkan selama 5 menit. Suspensi diambil $1 \mathrm{ml}$ dan ditambahkan $9 \mathrm{ml}$ air steril (pengenceran $10^{-2}$ ) lalu dikocok hingga homogen. Pengenceran dilakukan hingga pengenceran $10^{-4}$ selanjutnya inokulasi secara aseptik dilakukan dalam LAF dengan mengambil 0,1 $\mathrm{ml}$ suspensi dari pengenceran $10^{-4}$ kemudian dituangkan dalam petridish yang terisi media lalu diratakan keseluruh permukaan media menggunakan perata. Petridish kemudian di wrap dan diinkubasi. Jumlah koloni dihitung menggunakan hand colony counter kemudian dihitung populasi per gram tanah menggunakan rumus:

$\mathrm{CFU} / \mathrm{g}$ tanah $=\frac{\text { jumlah koloni } x \mathrm{fp}}{\text { berat } \operatorname{tanah}(\mathrm{g})}$

\section{Analisis Data}

Data hasil pengamatan dianalisis menggunakan analisis ragam berdasarkan uji $\mathrm{F}$ taraf $5 \%$. Uji Jarak Berganda Duncan dilakukan apabila terdapat pengaruh nyata perlakuan terhadap variabel pengamatan.

\section{HASIL DAN PEMBAHASAN}

\section{Analisis Sifat Kimia Tanah Sebelum dan Setelah Perlakuan}

Nilai $\mathrm{pH}$ setelah perlakuan jika dibandingkan dengan $\mathrm{pH}$ sebelum perlakuan pemupukan mengalami penurunan namun masih dalam kriteria $\mathrm{pH}$ netral (Tabel 1 dan Tabel 2)

Menurut Hartatik et al. (2006), kecenderungan penurunan $\mathrm{pH}$ pada tanah setelah perlakuan pupuk organik dikarenakan terjadi dekomposisi bahan organik yang mengeluarkan senyawa asam organik.

Pemberian pupuk hijau daun paitan dan waktu aplikasi berpengaruh sangat nyata dalam meningkatkan kadar $\mathrm{N}$ total tanah, $\mathrm{P}$ tersedia dan $\mathrm{K}$ tersedia tanah. Menurut Mwangi dan Mathenge (2014), pupuk hijau Tithonia memiliki potensi untuk meningkatkan kesuburan tanah. Pemupukan dengan Tithonia menyebabkan meningkatnya nitrogen $(\mathrm{N})$, fosfor $(\mathrm{P})$, kalium $(\mathrm{K})$, kalsium $(\mathrm{Ca})$, magnesium $(\mathrm{Mg})$, seng (Zn) kapasitas tukar kation dan bahan organik tanah di Ibadan Nigeria Menurut Sinaga (2009), bahan organik yang memiliki $\mathrm{C} / \mathrm{N}$ ratio rendah berarti bahan organik tersebut telah matang, sedangkan bahan organik yang masih memiliki $\mathrm{C} / \mathrm{N}$ ratio tinggi berarti bahan organik tersebut masih belum matang dan masih akan mengalami dekomposisi oleh mikroorganisme. Faktor yang mempengaruhi penghancuran bahah organik antara lain suhu, kelembaban, tata udara tanah, pengolahan tanah, $\mathrm{pH}$ dan jenis bahan organik.

Tabel 1. Analisis sifat kimia tanah sebelum perlakuan pemupukan

\begin{tabular}{lll}
\hline Parameter & Hasil Analisis \\
\hline $\mathrm{pH} \mathrm{H} \mathrm{H}_{2} \mathrm{O}$ & 7,4 & Kriteria * \\
$\mathrm{N}$ total $(\%)($ Walkley and Black) & 0,17 & Netral \\
$\mathrm{P}$ tersedia (ppm P) (Bray) & 12,6 & Rendah \\
$\mathrm{K}$ tersedia (me/100g) (N NH4OAc pH 7.0) & 0,85 & Tinggi \\
$\mathrm{C} / \mathrm{N}(\%)$ & 6,69 & Tinggi \\
\hline
\end{tabular}

${ }^{*}$ kriteria penilaian sifat-sifat kimia tanah menurut Balai Penelitian Tanah (2005). 


\section{Tinggi dan Berat Segar Brangkasan Bibit Kubis}

Berdasarkan analisis ragam, kombinasi perlakuan tidak berpengaruh nyata terhadap pertumbuhan bibit hari ke-0 dan ke-24 dan berpengaruh sangat nyata terhadap pertumbuhan bibit hari ke-48 dan hari-72. Pemupukan dengan kompos maupun daun paitan pada awal pembibitan, kandungan haranya dimungkinkan belum mampu diserap sepenuhnya oleh tanaman sehingga pertumbuhan bibit hari ke 0 dan ke-24 kurang optimal. Hasil penelitian Mwangi dan Mathenge (2014) menunjukkan bahwa pupuk hijau Tithonia menyediakan nitrogen dalam bentuk amonium. Kadar hara $\mathrm{N}$ yang siap dimanfaatkan untuk menunjang ertumbuhan tanaman diperlukan waktu sekitar 2-3 minggu.

Pengamatan pertumbuhan hari ke 48 dan 72 menunjukkan adanya pengaruh pemupukan terhadap tinggi bibit. Hal ini dimungkinkan karena unsur hara dari pemupukan baik kompos maupun daun paitan sudah tersedia bagi tanaman melalui proses dekomposisi sehingga bibit tumbuh optimal. Menurut Achieng et al. (2013), biomassa Tithonia kaya $\mathrm{N}$ dan $P$ yang dapat memberikan pengaruh terhadap pertumbuhan dan perkembangan.

Tabel 2. Pengaruh dosis pemupukan dan waktu aplikasi pupuk hijau daun paitan terhadap sifat kimia tanah pada tanah yang terinfestasi Plasmodiophora brassicae

\begin{tabular}{|c|c|c|c|c|c|c|c|c|c|c|c|}
\hline \multirow{2}{*}{$\begin{array}{l}\text { Waktu } \\
\text { Aplikasi } \\
\text { Pupuk } \\
\text { (HST) } \\
\end{array}$} & \multirow{2}{*}{ 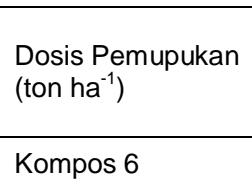 } & \multicolumn{2}{|l|}{$\mathrm{pH}$} & N Total (\%) & \multicolumn{3}{|c|}{$\begin{array}{l}\text { P Tersedia (ppm } \\
\text { P) }\end{array}$} & \multicolumn{2}{|l|}{$\begin{array}{l}\text { K Tersedia } \\
\text { (me/100g) }\end{array}$} & \multicolumn{2}{|l|}{$\mathrm{C} / \mathrm{N}(\%)$} \\
\hline & & $6,9 \pm 0,03$ & $\mathrm{bc}$ & $0,22 \pm 0,00$ & b & $9,1 \pm 0,35$ & $b$ & $2,15 \pm 0,03$ & de & $1,03 \pm 0,06$ & c \\
\hline \multirow{3}{*}{0} & Daun Paitan 6 & $6,8 \pm 0,06$ & $\mathrm{bc}$ & $0,22 \pm 0,00$ & $b$ & $8,9 \pm 0,11$ & $b$ & $1,87 \pm 0,02$ & $c$ & $0,98 \pm 0,07$ & $c$ \\
\hline & Daun Paitan 10 & $7,0 \pm 0,01$ & $\mathrm{~cd}$ & $0,27 \pm 0,01$ & c & $12,7 \pm 0,15$ & $d$ & $2,18 \pm 0,04$ & de & $1,11 \pm 0,10$ & $\mathrm{~cd}$ \\
\hline & Daun Paitan 16 & $6,7 \pm 0,01$ & $\mathrm{a}$ & $0,33 \pm 0,01$ & $d$ & $14,9 \pm 0,21$ & e & $1,72 \pm 0,01$ & $\mathrm{~b}$ & $1,17 \pm 0,11$ & $\mathrm{~cd}$ \\
\hline \multirow{4}{*}{7} & Kompos 6 & $7,1 \pm 0,06$ & $d$ & $0,49 \pm 0,01$ & $g$ & $18,9 \pm 0,18$ & $g$ & $2,25 \pm 0,02$ & ef & $0,55 \pm 0,06$ & $b$ \\
\hline & Daun Paitan 6 & $6,8 \pm 0,04$ & $a b$ & $0,20 \pm 0,01$ & b & $8,9 \pm 0,35$ & $b$ & $2,23 \pm 0,05$ & e & $1,26 \pm 0,07$ & $d$ \\
\hline & Daun Paitan 10 & $6,9 \pm 0,08$ & $\mathrm{bc}$ & $0,44 \pm 0,00$ & $f$ & $22,5 \pm 0,20$ & $\mathrm{~h}$ & $2,34 \pm 0,02$ & $\mathrm{fg}$ & $0,60 \pm 0,04$ & b \\
\hline & Daun Paitan 16 & $6,9 \pm 0,03$ & $\mathrm{bc}$ & $0,44 \pm 0,01$ & $f$ & $17,4 \pm 0,19$ & $f$ & $2,09 \pm 0,04$ & $d$ & $0,58 \pm 0,04$ & $b$ \\
\hline \multirow{4}{*}{14} & Kompos 6 & $6,8 \pm 0,04$ & $a b c$ & $0,35 \pm 0,02$ & $d$ & $17,2 \pm 0,30$ & $f$ & $2,36 \pm 0,04$ & g & $0,94 \pm 0,14$ & c \\
\hline & Daun Paitan 6 & $6,9 \pm 0,02$ & $c$ & $0,40 \pm 0,01$ & $\mathrm{e}$ & $9,9 \pm 0,26$ & c & $2,25 \pm 0,01$ & ef & $0,65 \pm 0,04$ & $b$ \\
\hline & Daun Paitan 10 & $6,8 \pm 0,02$ & $a b$ & $0,36 \pm 0,01$ & $\begin{array}{l}d \\
e\end{array}$ & $18,8 \pm 0,25$ & $g$ & $2,38 \pm 0,02$ & g & $0,61 \pm 0,04$ & b \\
\hline & Daun Paitan 16 & $6,7 \pm 0,03$ & $a b$ & $0,55 \pm 0,01$ & $\mathrm{~h}$ & $17,4 \pm 0,32$ & $f$ & $1,85 \pm 0,05$ & c & $0,45 \pm 0,01$ & b \\
\hline \multicolumn{2}{|c|}{ Tanpa pemupukan } & $6,9 \pm 0,11$ & $\mathrm{bc}$ & $0,16 \pm 0,03$ & $\mathrm{a}$ & $1,2 \pm 0,09$ & $\mathrm{a}$ & $0,64 \pm 0,05$ & $\mathrm{a}$ & $0,18 \pm 0,03$ & a \\
\hline
\end{tabular}

Keterangan: HST (hari setelah tanam). Angka pada kolom sama yang diikuti huruf sama tidak berbeda nyata pada uji jarak berganda Duncan taraf $5 \%$. Angka yang menyertai rata-rata adalah standar eror.

Tabel 3. Pengaruh dosis pemupukan dan waktu aplikasi pupuk hijau daun paitan terhadap tinggi dan berat segar brangkasan bibit kubis pada tanah terinfestasi $P$. brassicae

\begin{tabular}{|c|c|c|c|c|c|c|c|}
\hline \multirow{2}{*}{$\begin{array}{l}\text { Waktu Aplikasi } \\
\text { Pupuk (HST) }\end{array}$} & \multirow{2}{*}{$\begin{array}{l}\text { Dosis Pemupukan } \\
\left(\text { ton } \mathrm{ha}^{-1} \text { ) }\right.\end{array}$} & \multicolumn{4}{|c|}{ Tinggi Bibit $(\mathrm{cm})$ hari ke- } & \multirow{2}{*}{\multicolumn{2}{|c|}{$\begin{array}{l}\text { Berat Segar Brangkasan } \\
\text { Bibit Kubis tanpa Akar (g) }\end{array}$}} \\
\hline & & 0 & 24 & 48 & 72 & & \\
\hline \multirow{4}{*}{0} & Kompos 6 & 2,292 & 5,217 & 9,625 & 12,125 & $16,45 \pm 0,86$ & c \\
\hline & Daun Paitan 6 & 2,408 & 4,083 & 8,208 & 10,875 & $10,54 \pm 0,50$ & $a b$ \\
\hline & Daun Paitan 10 & 2,108 & 4,583 & 8,417 & 10,917 & $10,85 \pm 0,54$ & $a b$ \\
\hline & Daun Paitan 16 & 2,308 & 5,833 & 7,667 & 7,792 & $18,58 \pm 2,13$ & c \\
\hline \multirow{4}{*}{7} & Kompos 6 & 1,942 & 5,542 & 11,625 & 14,250 & $15,45 \pm 1,42$ & c \\
\hline & Daun Paitan 6 & 2,150 & 4,833 & 8,458 & 11,542 & $8,95 \pm 0,97$ & $a b$ \\
\hline & Daun Paitan 10 & 2,133 & 5,208 & 8,958 & 11,667 & $9,40 \pm 1,99$ & $a b$ \\
\hline & Daun Paitan 16 & 2,300 & 5,283 & 9,208 & 11,917 & $9,45 \pm 0,32$ & $a b$ \\
\hline \multirow{4}{*}{14} & Kompos 6 & 2,267 & 5,292 & 9,792 & 12,375 & $11,28 \pm 0,39$ & $b$ \\
\hline & Daun Paitan 6 & 2,442 & 5,542 & 9,417 & 12,458 & $9,80 \pm 0,43$ & $a b$ \\
\hline & Daun Paitan 10 & 2,450 & 5,708 & 10,542 & 13,042 & $8,96 \pm 0,74$ & $a b$ \\
\hline & Daun Paitan 16 & 2,017 & 4,792 & 10,000 & 13,750 & $10,90 \pm 0,65$ & $a b$ \\
\hline \multicolumn{2}{|c|}{ Tanpa pemupukan } & 2,250 & 4,417 & 9,208 & 12,250 & $7,53 \pm 0,47$ & $\mathrm{a}$ \\
\hline
\end{tabular}

Keterangan: HST (hari setelah tanam). Angka pada kolom sama yang diikuti huruf sama tidak berbeda nyata pada uji jarak berganda Duncan taraf $5 \%$. Angka yang menyertai rata-rata adalah standar eror.

Pengendalian Infeksi Akar Gada pada Pembibitan Kubis dengan Pupuk Hijau Daun Paitan

Diah Ayu Pratiwi, Hardjono Sri Gutomo, Hadiwiyono 
Berdasarkan analisis ragam, waktu aplikasi berpengaruh sangat nyata terhadap berat segar brangkasan bibit kubis. Waktu aplikasi 0 HST memiliki rerata berat segar brangkasan paling tinggi yaitu berat segar brangkasan bibit kubis perlakuan dosis pemupukan daun paitan 16 ton ha ${ }^{-1}$ yaitu $12,98 \mathrm{~g}$, namun rerata tersebut belum melampaui rerata berat brangkasan bibit perlakuan kompos 6 ton ha ${ }^{-1}$ yang memiliki rerata paling tinggi sebesar $14,39 \mathrm{~g}$. Hal ini diduga karena daun paitan diaplikasikan dalam bentuk pupuk hijau maka harus terdekomposisi dahulu agar unsur haranya dapat diserap tanaman, sementara kompos kandungan haranya sudah siap diserap oleh tanaman sehingga dapat menunjang pertumbuhan bibit. Hal ini didukung hasil penelitian Shokalu et al. (2010) yang menyatakan bahwa hasil dari pemupukan kompos lebih tinggi daripada hasil pemupukan Tithonia. Hal ini dikaitkan dengan ketersediaan nitrogen dari pupuk kompos yang tinggi dan cepat tersedia bagi tanaman.

\section{Intensitas Penyakit dan Analisis Dampak Lingkungan}

Penambahan bahan organik dapat mempengaruhi kondisi tanah (sifat fisik, kimia dan biologi) sehingga dimungkinkan dapat mengurangi serangan akar gada. Menurut Bailey dan Lazarovits (2005), pupuk hijau dapat menurunkan kejadian penyakit tular tanah setelah 2 tahun meskipun tingkat inokulum patogen sama atau meningkat 2-4 kali lipat. Pemupukan daun paitan 16 ton ha ${ }^{-1}$ memiliki intensitas penyakit yang lebih tinggi jika dibandingkan dengan pemupukan daun paitan 10 ton ha ${ }^{-1}$ yaitu sebesar 20,37\% (Tabel 4). Pemupukan daun paitan 16 ton ha ${ }^{-1}$ diduga menyebabkan tanaman lebih rentan terhadap serangan penyakit akar gada. Hal ini mungkin berkaitan dengan kandungan $\mathrm{N}$ yang dihasilkan pupuk hijau paitan 16 ton ha ${ }^{-1}$ yang berlebih. Menurut Soepardi (1983), pemberian $N$ berlebihan menyebabkan tanaman menjadi sukulen (banyak mengandung air), batang-batang lemah mudah roboh dan daya tahan tanaman terhadap penyakit berkurang dan mudah terserang hama.

Hasil penelitian menunjukkan bahwa populasi mikrob yang sering ditemukan di dalam tanah adalah bakteri (Tabel 4). Hal ini sesuai dengan pernyataan
$14,10 \mathrm{~g}$. Hal ini diduga karena aplikasi pupuk yang lebih awal sehingga unsur hara dari pemupukan dapat segera dimanfaatkan bibit kubis untuk menunjang pertumbuhannya. Dilihat secara faktorial, rata-rata Rao (1994), bahwa bakteri merupakan kelompok mikroorganisme yang paling dominan di tanah. Populasi jamur tidak ditemukan pada pengenceran $10^{-4}$, hal ini diduga karena pengenceran bertingkat yang dilakukan terlalu rendah sehingga tidak ditemukan populasi jamur. Populasi Actinomycetes paling tinggi pada pemupukan 10 ton ha ${ }^{-1}$ yaitu 16,89 $10^{4}$ CFU $g^{-1}$ tanah dan populasi dan paling rendah 6,30 $10^{4}$ CFU g ${ }^{-1}$ tanah pada perlakuan tanpa pemupukan.

Penambahan pupuk hijau maupun sisa-sisa tanaman bertujuan untuk memanipulasi kualitas tanah sehingga mampu menunjang pertumbuhan tanaman dan mengendalikan penyakit tular tanah. Pertumbuhan bibit kubis yang baik diduga dipengaruhi unsur hara yang tersedia dalam tanah. Penambahan pupuk hijau daun paitan dapat meningkatkan kandungan $\mathrm{N}$ total, $\mathrm{P}$ tersedia dan $\mathrm{K}$ tersedia tanah. Crespo et al. (2011) menjelaskan bahwa tanaman yang kecukupan unsur $\mathrm{K}$ dinding selnya akan lebih tebal dan memberikan stabilitas jaringan sehingga tanaman lebih tahan terhadap hama dan penyakit. Pendekomposisian bahan organik tidak terlepas dari adanya mikrob tanah yang berperan sebagai dekomposer. Ketersediaan unsur hara juga dipengaruhi oleh $\mathrm{pH}$ tanah. Menurut Sudaryono (2009), ketersediaan P dalam tanah bagi tanaman dipengaruhi oleh kemasaman tanah. Ketersediaan optimum dari unsur $\mathrm{P}$ bagi tanaman diperoleh pada $\mathrm{pH}$ 5,5-7,0.

Pemupukan pupuk hijau daun paitan dengan dosis 10 ton $^{-1} \mathrm{~h}^{-1}$ mampu menurunkan intensitas penyakit mencapai $10,18 \%$. Penurunan intensitas penyakit ini kemungkinan dipengaruhi oleh adanya mikrob lain yang ada dalam tanah seperti bakteri, jamur, dan Actinomycetes. Menurut Mazzola (2004), struktur komunitas mikroba tanah merupakan indikator kesehatan tanah yang sangat baik. Berdasarkan hasil penelitian, pemupukan pupuk hijau daun paitan 10 ton $\mathrm{ha}^{-1}$ memiliki populasi bakteri terendah dibandingkan perlakuan lainnya, sedangkan populasi Actinomycetes

Tabel 4. Pengaruh dosis pupuk hijau daun paitan terhadap intensitas penyakit akar gada dan analisis dampak lingkungan pada tanah terinfestasi $P$. brassicae

\begin{tabular}{lllllll}
\hline Dosis Pupuk (ton ha & -1 \\
& $\begin{array}{l}\text { Intensitas Penyakit } \\
\text { Akar Gada (\%) }\end{array}$ & \multicolumn{3}{c}{ Populasi Mikrob Tanah $\left(10^{4}\right.$ CFU g $^{-1}$ tanah) } \\
& $11,11 \pm 3,06$ & a & $95,22 \pm 22,30$ & ab & $8,89 \pm 2,54$ & Actinomycetes \\
\hline Kompos 6 & $25,92 \pm 3,70$ & b & $132,33 \pm 23,34$ & b & $13,89 \pm 5,04$ & a \\
Daun paitan 6 & $10,18 \pm 3,19$ & a & $58,00 \pm 7,21$ & a & $16,89 \pm 2,29$ & a \\
Daun paitan 10 & $20,37 \pm 6,24$ & ab & $80,00 \pm 29,99$ & ab & $14,89 \pm 2,36$ & a \\
Daun paitan 16 & $50,00 \pm 11,11$ & C & $52,00 \pm 9,80$ & a & $6,30 \pm 1,78$ & a \\
Tanpa pemupukan &
\end{tabular}

Keterangan: CFU: Colony Forming Units. Angka pada kolom sama yang diikuti huruf sama tidak berbeda nyata pada uji jarak berganda Duncan taraf $5 \%$. Angka yang menyertai rata-rata adalah standar eror. 
tertinggi dibandingkan dengan perlakuan lainnya (Tabel 4).

Keberadaan Actinomycetes diduga mampu untuk menekan patogen tular tanah seperti $P$. brassicae. Cicu (2006) mengungkapkan Actinomycetes secara alami berperan menekan patogen melalui proteksi pada akar sehingga ketahanan tanaman inang terhadap infeksi patogen meningkat. Selain itu $\mathrm{pH}$ tanah juga berpengaruh terhadap perkembangan penyakit akar gada. Pemupukan pupuk hijau daun paitan cenderung menurunkan $\mathrm{pH}$ tanah pada kisaran 6,8-7,0 sementara menurut Rastas et al. (2012), penyakit akar gada sering ditemukan pada tanah yang memiliki nilai $\mathrm{pH}$ berkisar antara 5-7,6, menimbulkan serangan yang hebat pada $\mathrm{pH} 5,7$ dan serangan menurun pada $\mathrm{pH} 7,8$. Menurut Riascos et al. (2011), pertumbuhan dari tanaman yang terinfeksi akar gada lambat dan menyebabkan terjadinya klorosis karena penyerapan air dan nutrisi oleh akar terhambat sehingga pada akhirnya menyebabkan tanaman yang terinfeksi pertumbuhannya tidak normal dan hasilnya menurun.

\section{KESIMPULAN DAN SARAN}

Pupuk hijau daun paitan ( $T$. diversifolia) cenderung efektif dalam menekan serangan $P$. brassicae penyebab akar gada serta mampu menunjang pertumbuhan bibit kubis. Pemupukan pupuk hijau daun paitan 10 ton ha ${ }^{-1}$ mampu menurunkan intensitas serangan $P$. brassicae mencapai $10,18 \%$. Waktu aplikasi pupuk hijau daun paitan 0 HST memiliki rerata berat segar brangkasan tertinggi yaitu $14,10 \mathrm{~g}$.

\section{DAFTAR PUSTAKA}

Achieng J, Ouma G, Odhiambo G. 2013. Use of organic inputs in management of alfisols and ultisols for sustainable maize production in western Kenya. American J Exp Agric 3(4): 884-895. DOI: 10.9734/AJEA/2013/4733.

Baharuddin, Hambali Irma S, Masjkur Z. 2002. Penggunaan bakteri antagonis dalam menekan intensitas serangan penyakit akar gada $(P$. brassicae) pada kubis (Brassica oleraceae), hal. 63-67, Dalam: Datnoff et al.(eds). Prosiding Seminar IImiah dan Pertemuan Tahunan PEI, PFI \& HPTI XV Sul-Sel. Maros 29 Oktober 2002. Jur HPT Fak Pert Kehutanan Unhas.

Bailey KL, Lazarovits G. 2005. Suppressing soilborne diseases with residue management and organic amendments. Soil Till Res 72: 169-180. DOI: 10.1016/S0167-1987(03)00086-2.

Balai Penelitian Tanah. 2005. Petunjuk teknis analisis kimia tanah, tanaman, air, dan pupuk. Bogor (ID): Balai Penelitian Tanah.

BPS [Badan Pusat Statistika]. 2013. Luas panen, produksi dan produktivitas kubis 2009-2013. URL: www.bps.go.id. Diakses 22 September 2014.
Cicu. 2006. Penyakit akar gada (Plasmodiophora brassicae wor.) pada kubis-kubisan dan upaya pengendaliannya. J Litbang Pert 25(1): 1621. http://pustaka.litbang.deptan.go.id. Diakses pada 20 November 2013.

Crespo G, Ruiz TE, Alvarez J. 2011. Effect of green manure from Tithonia ( $T$. diversifolia) on the establishment and production of forage of $P$. purpureum cv. Cuba CT-169 and on some soil properties. Cuban J Agric Sci 45(1): 79-82. URL: http://www.cienciaanimal.org/cuban-journal-ofagricultural science/ articles/V45-N1-Y2011-P079G-Crespo.pdf. Diakses pada 6 November 2014.

Dixon GR. 2009. The occurrence and economic impact of clubroot disease. J Plant Growth Regul 28: 194-202. DOI: 10.1007/s00344-009-9090-y.

Hartatik WD, Setyorini, Widati S. 2006. Laporan penelitian teknologi pengelolaan hara pada budidaya pertanian organik. Bogor (ID): Balai Penelitian Tanah.

Jama B, Palm CA, Buresh RJ, Niang A, Gachengo C, Nziguheba G, Amadalo B. 2000. Tithonia diversifolia as a green manure for soil fertility improvement in western Kenya. Agrf Syst 49: 201221. DOI:10.1023/A:1006339025728.

Lungu OIM, Deynoodt RFP. 2008. Acidification from long-term use of urea and its effect on selected soil properties. Afr J Food Agric Nut Develop 8(1): 6376. URL: http://www.bioline.org.br. Diakses pada 22 Agustus 2014.

Mazzola M. 2004. Assessment and management of soil microbial community structure for disease suppression. Ann Rev Phytopathol 42: 35-59. DOI: 10.1146/annurev.phyto.42.040803.140408.

Mwangi PM, Mathenge PW. 2014. Comparison of Tithonia ( $T$. diversifolia) green manure, poultry manure and inorganic sources of nitrogen in the growth of kales ( $B$. oleraceae) in Nyeri county Kenya. Afr J Food Agric Nut Develop 14(3): 87918808. DOI:10.5539/jas.v6n5p34.

Rao NS. 1994. Mikroorganisme tanah dan pertumbuhan tanaman. Jakarta (ID): UI Press.

Rastas M, Latvala S, Hannukkala A. 2012. Occurrence of Plasmodiophora brassicae in finnis turnip rape and oilseed rape fields. Agric Food Sci 21: 141-158. DOI: 10.1007/s10343-014-0329-6.

Riascos D, Ortiz E, Quintero D, Montoya L, Hoyoz L. 2011. Histopathological and morphological alterations caused by Plasmodiophora brassicae in Brassica oleracea L. Agro Col 29(1): 57-61. URL: http://www.redalyc.org/articulo.oa?id=1803225730 08. Diakses pada 2 November 2014.

Semangun H. 2007. Penyakit-penyakit tanaman hortikultura di Indonesia. Yogyakarta (ID): Gadjah Mada University Press.

Shokalu, Olubukola A, Aderemi O, Tinuke D, Henry A, Oladipupo J, Azzez, Adewoyin. 2010. Comparing the use of Tithonia diversifolia and compost as soil 
amendments for growth and yield of Celosia argentea. NY Sci J 3(6): 133-138. URL: www.sciencepub.net. Diakses pada 5 Juni 2014.

Sinaga. 2009. Pengaruh penambahan arang sekam padi dan arang ilalang. URL: http://repository. usu.ac.id. Diakses 25 September 2014.
Soepardi G. 1983. Sifat dan ciri tanah. Bogor (ID): Jurusan Tanah, Fakultas Pertanian, Institut Pertanian Bogor. 